\title{
Seizures-intellectual disability due to hydroxylysinuria syndrome
}

INSERM

\section{Source}

INSERM. (1999). Orphanet: an online rare disease and orphan drug data base. Seizuresintellectual disability due to hydroxylysinuria syndrome. ORPHA:79156

Seizures-intellectual disability due to hydroxylysinuria syndrome is characterised by hydroxylysinuria, myoclonic and motor seizures and intellectual deficit. It has been described in a brother and sister born to consang uineous parents and in one unrelated patient. 